\title{
Role of the serotoninergic system in the sodium appetite control
}

\author{
LUíS C. REIS \\ Departamento de Ciências Fisiológicas, Instituto de Biologia, Universidade Federal Rural do Rio de Janeiro, \\ BR 465, km 7, 23890-000 Seropédica, RJ, Brasil \\ Manuscript received on September 22, 2005; accepted for publication on September 27, 2006; \\ presented by LUCIA MENDONÇA PREVIATO
}

\begin{abstract}
The present article reviews the role of the serotoninergic system in the regulation of the sodium appetite. Data from the peripheral and icv administration of serotoninergic (5-HTergic) agents showed the participation of 5-HT2/3 receptors in the modulation of sodium appetite. These observations were extended with the studies carried out after brain serotonin depletion, lesions of DRN and during blockade of 5-HT2A/2C receptors in lateral parabrachial nucleus (LPBN). Brain serotonin depletion and lesions of DRN increased the sodium appetite response, in basal conditions, after sodium depletion and hypovolemia or after beta-adrenergic stimulation as well. These observations raised the hypothesis that the suppression of ascending pathways from the DRN, possibly, 5-HTergic fibers, modifies the angiotensinergic or sodium sensing mechanisms of the subfornical organ involved in the control of the sodium appetite. 5-HTergic blockade in LPBN induced to similar results, particularly those regarded to the natriorexigenic response evoked by volume depletion or increase of the hypertonic saline ingestion induced by brain angiotensinergic stimulation. In conclusion, many evidences lead to acceptation of an integrated participation resulting of an interaction, between DRN and LPBN, for the sodium appetite control.
\end{abstract}

Key words: hydroelectrolyte balance, sodium appetite, 5-HTergic system, dorsal raphe nucleus, lateral parabrachial nucleus, 5-HTergic agents.

\section{INTRODUCTION}

THE ION SODIUM PLAYS CRITICAL ROLE IN THE MAINTENANCE OF THE VOLUME OF EXTRACELLULAR FLUID: INFLUENCE OF THE RENIN-ANGIOTENSINALDOSTERONE SYSTEM

The dynamic balance of the milieu interieur is a sine qua non condition for maintenance of life (Bernard 1878, Andersson 1978, Denton et al. 1996, Voisin and Bourque 2002, Weisinger et al. 2004). The homeostatic prevention of perturbations of the extracellular fluid (ECF) volume and tonicity is dependent on harmonic efficiency of multiple physiological systems.

It is well known the role of the ion sodium, major ionic component of ECF, as a crucial factor for the

E-mail: lcreis@ufrrj.br; lcreis@click21.com.br cellular excitability and the maintenance of the tonicity and circulating volume (Andersson 1978, Daniels and Fluharty 2004, Weisinger et al. 2004). Experimental evidences have demonstrated that sodium appetite oscillation is monitored by a putative sodium sensing mechanism limited to subfornical organ (SFO). The $\mathrm{Na}_{\mathrm{x}}^{+}$ channels within the SFO, recently described, represent a functional category of sensor neurons distinct from osmosensor neurons (Andersson 1978, Denton et al. 1996, Goldin et al. 2000, Hiyama et al. 2002, 2004, Weisinger et al. 2004) previously theorized from data and conceptions of Andersson (Andersson 1952, 1971, 1978, Andersson and McCann 1954). Another class of sodium sensing neurons is confined to magnocellular subregion of the supraoptic nucleus (SON). Local osmosensitivity is operated in vasopressinergic neurons through intrin- 
sic stretch-inactivated cation channels. Sodium detection occurs following acute regulation of the permeability and chronic changes in $\mathrm{Na}^{+}$channels gene expression (Voisin and Bourque 2002).

Terrestrial vertebrates developed physiological systems implicated with the control of the ECF volume from the challenges raised by the environment, e.g., deficit and excessive offer of $\mathrm{NaCl}$ (Denton 1984, Schulkin 1991, Fitzsimons 1998, Weisinger et al. 2004). The physiological systems related both to the sodium and the ECF volume homeostasis include the renin-angiotensin-aldosterone (RAAS), atrial natriuretic peptide (ANP) and oxytocin (OT) systems (Fitzsimons 1998, McCann et al. 1997, 2003, Antunes-Rodrigues et al. 2004, Daniels and Fluharty 2004, McKinley and Johnson 2004, Weisinger et al. 2004, Saavedra 2005).

Angiotensin (ANG) is peripherally generated by the catalysis from a circulating alpha2-globulin, the angiotensinogen (Reid et al. 1978, Fitzsimons 1998, Saavedra 2005). Renin, the enzyme secreted by juxtaglomerular cells of the afferent renal arteriole, participates in this reaction in response to hyponatremia, ECF volume shrinkage and hypotension. From this reaction results a decapeptide, ANG I, considered a prohormone. Circulating ANG I undergoes the catalytic action of the angiotensin converting enzyme (ACE) expressed in several territories. However, the lung constitutes the largest surface which produces this enzyme. Following this stage, occurs the formation of ANG II, potent vasoconscrictor agent and also implied on the increase of the renal sodium reabsorption and dipsogenic and sodium appetite expression.

\section{RENIN-ANGIOTENSIN-ALDOSTERONE, ANP AND} OXYTOCIN SYSTEMS AND THE RENAL SYMPATHETIC INNERVATION CONSTITUTE INTEGRATED SYSTEMS OF CONTROL OF THE SODIUM RENAL REABSORPTION

The kidney mediates the regulation of the sodium reabsorption in mammals. Thus, the increase of the RAAS activity and subsequent increase of ANG II and aldosterone plasma levels stimulated by the hyponatremia constitute critical variables for the homeostatic restoration of the ECF volume. During hypernatremia condition and therefore higher ECF volume, occurs a depression of the RAAS activity with concomitant increase of
ANP and probably oxytocin (OT), culminating with the increase of the renal sodium excretion (Fitzsimons 1998, McCann et al. 2003, Antunes-Rodrigues et al. 2004).

ANP, a natriuretic hormone produced by cardiomiocytes, is released after stretch of the wall of right atrium provoked by blood volume expansion (AntunesRodrigues et al. 1991, 2004, DeBold et al. 1996). OT, a hormone produced by magnocellular neurons of the hypothalamic paraventricular nucleus (PVN) is also a natriuretic hormone whose secretion is increased after ECF hypertonic expansion (Soares et al. 1999, Ventura et al. 2002, Antunes-Rodrigues et al. 2004). Interestingly, OT release is dependent on nitrergic activation in the basomedial hypothalamus and the natriuretic response. On the other hand, it is also dependent on nitrergic mediation in the renal tubular sites (Soares et al. 1999, Ventura et al. 2002, McCann et al. 2003, AntunesRodrigues et al. 2004).

In addition, it has been suggested that ANPergic neurons in hypothalamus excite the oxytocinergic neurons in the PVN and SON to release oxytocin from the neurohypophysis which by plasma stimulate the release of ANP from the atria (McCann et al. 1997, 2003, Antunes-Rodrigues et al. 2004).

After chronic sodium deprivation and subsequent hyponatremia, renal sensors identify and measure the magnitude of this error. In this context, renal and endocrine mechanisms related to sodium, and consequently water maintenance, are activated. Furthermore, sensors located in the juxtaglomerular apparatus (JGA) recognize reduction in natremia, extracellular fluid volume, blood pressure and tubular renal sodium content. JGA is an anatomo-functional unit constituted by the juxtaglomerular cells of the afferent arteriole, mesangial cells and macula densa. This system controls tubuleglomerular balance and activates renin angiotensin aldosterone system (RAAS). It subsequently increases the renin release, the systemic ANG II generation and aldosterone secretion (Fitzsimons 1998, Schnermann and Levine 2003). Mediation of renal sodium reabsorption during the ECF volume shrinkage is intensified by RAAS. Simultaneously, it is observed a reduction on cardiac ANP releasing. Furthermore, it is also postulated an OT plasma level decreasing (McCann et al. 2003, Antunes-Rodrigues et al. 2004). 
The renal autonomic tubular innervation seems to constitute another pathway for sodium excretion control. Renal dennervation induces a transitory increase of the sodium excretion. On the other hand, electric stimulation of renal nerve reduces natriuretic response through increase of the tubular sodium reabsorption (DiBona 2001). These observations were reinforced by evidence that central sympatholytic action induces an increase of the renal sodium excretion (Saad et al. 2002).

Regulation of $\mathrm{Na}^{+}$reabsorption in the kidney constitutes a critical mechanism for ECF volume and longterm blood pressure control (Harris et al. 1996, CarusoNeves et al. 2004). In this context, the $\mathrm{Na}^{+}$-ATPase, a transepithelial sodium transporter on the proximal tubule have deserved special attention. This transporter is an important homeostatic target of brain and circulating signals for fine regulation of $\mathrm{Na}^{+}$reabsorption. For example, it has been demonstrated that ANP inhibits the proximal $\mathrm{Na}^{+}$-ATPase by the NPR-TO/guanilate cyclase/ cGMP pathway (Harris et al. 1996, Caruso-Neves et al. 2004). Similarly, natriuretic effect of OT is dependent on guanilate cyclase/cGMP pathway but through NO synthesis (Soares et al. 1999). Therefore, ANG II and ANP (OT as well) act antagonistically in the proximal tubule as regulators of ECF volume. These evidences have disclosed a wider homeostatic possibility by which both brain and peripheral signals to be integratively acting on the salt appetite and sodium excretion modulation (McCann et al. 2003, Antunes-Rodrigues et al. 2004).

\section{SODIUM APPETITE CONTROL: SIGNALING FOR SODIUM APPETITE EXPRESSION}

Following a prolonged sodium deficit elicited by a restriction on dietary sodium access, sensory systems are activated and lead to humoral signaling. By contrast, when sodium offer exceed the physiological set point, there is an increase of the ECF volume involving a depression of the RAAS activity. This response is followed by a concomitant increase of ANP, and probably OT, release and consequent sodium appetite inhibition. In this context, the hypothalamus and the anterior-ventral region of the third ventricle (AV3V) are involved in the ANP release induced by the blood volume expansion and by signals originated in baroreceptors and peripheral volume receptors (Antunes-Rodrigues et al. 1991, 2004,
Johnson and Thunhorst 1997).

Visceral sensory signals relayed from the activation of volume receptors and baroreceptors, ascend to the forebrain after synapsing within the brainstem (Denton 1984, Fitzsimons 1998). The nucleus tractus solitarius (NTS) and lateral parabrachial nucleus (LPBN) constitute the main circuits that relay information about the blood pressure and the blood volume elevation in the kidney as well as in vascular endothelium (Denton 1984, Schulkin 1991, Fitzsimons 1998, Daniels and Fluharty 2004). Signals concerning to the tubular sodium concentration along macula densa, can also achieve the brain purposing to activate mechanisms to regulate the sodium excretion and salt ingestion. The perspective of this possibility was subject matter of investigation in which it showed that neurons of SFO receive signaling from renal afferents (Ciriello 1998).

In another experimental approach, electrophysiological records were obtained in oxytocinergic neurons of PVN after electric stimulation of renal afferent nerves in rats (Ciriello 1997). In this article, Ciriello presented circumstantial evidence that the kidney sense variations in the sodium tubular concentration (and therefore of the ECF volume) relaying it to the brain. For this conclusion, the author showed that ANG II excited-neurons of SFO which project toward PVN are responsive to nerve afferent stimulation. Interestingly, central inhibition of ANG II generation or their actions blockade prevented the sensory activation after the volume depletion (Fitch and Weiss 2000). In this context, Thunhorst et al. (1996) have finaly demonstrated that the integrity of the renal nerves is important for the normal elaboration of salt appetite in response to hypovolemia/hypotension. This evidence joined to those achieved by Ciriello (1997, 1998) have undoubtedly corroborated the hypothesis by which the kidney plays a role in the activation of a visceral sensory mechanism implicated in the neuroendocrine and behavioral responses concerning the water and electrolyte control.

Besides being a potent dipsogenic agent, ANG II also increases the expression of the sodium appetite after hyponatremia and concomitant volume depletion. Structures of the lamina terminalis endowed with ANG II receptor are involved on sodium appetite after hypovolemia (Fitzsimons 1998, McKinley et al. 2003). AT1 
receptors located in the forebrain, especially in the circumventricular organs (CVO's), have been implicated in the mediation of this homeostatic behavior. Moreover, ANG II stimulates $c$-fos expression in the OVLT and SFO (Denton et al. 1996, Johnson and Thunhorst 1997, Fitzsimons 1998). In turn, aldosterone released during the same physiological context, acts synergistically increasing the expression of ANG II receptors in the SFO (Denton 1984, Schulkin 1991, Fitzsimons 1998, Daniels and Fluharty 2004).

The role of the salt taste in the salt ingestion was recently reassessed (Daniels and Fluharty 2004). In this work, the authors regarded that sodium intake is unique among ingestive behaviors that defines precisely a specific sensory channel responsible for the sensory qualities thereof is being ingested. Sensory neurons arising from gustatory system send fibers through chorda tympani afferents which it directs to dorsal portion of the NTS. The somatotopic organization of the gustatory system in the NTS constitutes the beginning of the central gustatory neuroaxis. Neurophysiological evidence showed that gustatory system plays a crucial role in the detection, acceptability and ingestion of salt in a coordinated way. In turn, chorda tympani axons synapse with the NTS gustatory neurons and receive gabaergic inhibitory innervation whose firing rate is modulated by ANG IICVO's, thalamic, cortical and limbic inputs.

\section{FOREBRAIN STRUCTURES AND SODIUM APPETITE REGULATION}

The central mediation of the sodium appetite is dependent on integrity of structures of the lamina terminalis and of the wall of AV3V region, e.g., subfornical organ (SFO), organum vasculosum laminae terminalis (OVLT) and dorsal and ventral preoptic median nucleus (MnPOd, MnPOv) and hypothalamic structures (AntunesRodrigues and Covian 1963, Covian and AntunesRodrigues 1963, Miselis 1981, Denton 1984, Schulkin 1991, Johnson and Thunhorst 1997, Fitzsimons 1998, Thunhorst et al. 1999, McCann et al. 2003, McKinley et al. 2003, Antunes-Rodrigues et al. 2004, McKinley and Johnson, 2004, Weisinger et al. 2004). Central integration of the excitatory and inhibitory inputs for the control of sodium appetite requires interaction among neural circuits of the lamina terminalis and, amigdala, septal area and structures of the brainstem (Denton 1984, Fitzsimons 1998, Antunes-Rodrigues et al. 2004). AT1 subtype receptors for ANG II were identified in those structures and icv microinjection of losartan, an AT1 antagonist, has been related to the decrease in the sodium and water ingestion. Moreover, ANG II neurons, located in the lamina terminalis, co-express ACE, especially in OVLT and SFO (Blair-West et al. 1994, Fitzsimons 1998, McKinley et al. 2003, Saavedra 2005). Functional evidence of ANG I-ANG II conversion into the SFO was obtained after icv or intra-SFO administration of captopril. It has abolished the effects produced by systemic low dose of captopril (Thunhorst et al. 1989). Therefore, it was suggested that SFO contains an intrinsic RAS, constituting in this way a relay that connects the brain with peripheral RAS for mediating of the hydroelectrolytic balance and to provide a drive mechanism for the sodium appetite regulation (Fitzsimons 1998, Weisinger et al. 2004). Recent evidences clearly showed that SFO constitutes the center of the sodium appetite behavior where sodium concentration is inherently monitored by $\mathrm{Na}_{\mathrm{x}}^{+}$channel sensing mechanism (Hiyama et al. 2004). The efferent SFO projections are especially directed to two areas: preoptic area of the AV3V region where terminals are distributed, particularly in MnPO, periventricular nucleus, $(\mathrm{PeVN})$ and OVLT. Moreover, endings from the SFO neurons project to hypothalamus where they synapse with magnocellular neurons of the SON and PVN.

Despite of some controversy, it is admitted the involvement of SFO AT1 receptors on the natriorexigenic response induced by volume depletion (Fitzsimons 1998, Menani et al. 1998b, McKinley et al. 2003). Both, SFO and OVLT, are CVOs, therefore they lack bloodbrain barrier (BBB). This functional property provides free access for some humoral signals that are recognized and monitored. ANG II icv administration as well as paradigms that evoke volume depletion, stimulate the sodium appetite. In both conditions there is an increase of brain angiotensinergic activity (Fitzsimons 1998). Action of ANG II in SFO also induces enhance of the blood pressure, reaction that would be associated to the dipsogenic and sodium appetite responses in parallel to physiological contexts (Fitzsimons 1998). Systemic or per os administration of low dose of captopril increases 
circulating ANG I levels. In this condition, the ACE inhibitor just acts peripherally. Therefore, the increase of brain ANG I availability provides the manifestation of the sodium appetite through mechanism that requires central conversion of ANG I to ANG II (Elfont et al. 1984, Moe et al. 1984, Fitzsimons 1998, Ventura et al. 2001, Badauê-Passos et al. 2003).

Hypothalamus and the lamina terminalis, structures related to the hydroelectrolytic regulation, also express receptors and binding sites for ANP and, therefore, its participation has been widely postulated for the control of sodium excretion and salt ingestion (Quirion 1989, Brown and Czarnecki 1990, Saavedra and Kurihara 1991, Gutkowska et al. 1997, McCann et al. 2003, Antunes-Rodrigues et al. 2004). Furthermore, the existence of ANPergic neurons is hypothesized in parallel to the angiotensinergic neurons, which subserve the water and electrolyte balance (Antunes-Rodrigues et al. 1991, 2004, Reis et al. 1994, McCann et al. 2003). When ANP is administered by icv route, it inhibits the preference for saline in sodium-depleted rats (Antunes-Rodrigues et al. 1986). Additionally, the central injection of ANP attenuates the exaggerated sodium appetite in spontaneously hypertensive rats (Itoh et al. 1986). From these studies, it postulated that inhibitory action of ANP is probably mediated by neurons of the same structures which are excited by ANG II.

Binding sites for OT were also identified in hypothalamus and lamina terminalis structures related to regulation of the sodium appetite (Johnson and Thunhorst 1997, McCann et al. 2003, Antunes-Rodrigues et al. 2004). Furthermore, the evidence that neural OT release in SFO alters the excitability of ANG II-sensitive neurons, raises the possibility that the oxytocinergic transmission modulates the ANG II actions (Hosono et al. 1999, Daniels and Fluharty 2004). In this context, icv administration of OT induces a decrease of salt ingestion in sodium-depleted rats (Stricker and Verbalis 1996). Reinforcing this observation was demonstrated by the fact that central administration of OT antagonist attenuates the inhibition of salt ingestion induced by OT in rats submitted to the increase of the plasma osmolality (Blackburn et al. 1995, Stricker and Verbalis 1996, Johnson and Thunhorst 1997, Fitts et al. 2003, Daniels and Fluharty 2004). This comprehension was expanded with the evidence that increased OT gene expression induces a reduced sodium appetite response and, that sodium consumption challenged by volume depletion increases the Fos protein expression in oxytocinergic neurons of PVN in rats (Franchini and Vivas 1995, Franchini et al. 2003). Finally, it was demonstrated that knock-out mice for the OT gene express exaggerated sodium appetite after fluid deprivation or following the hypovolemia induced by sc injection of hyperoncotic substance (Amico et al. 2001, Rigatto et al. 2003).

\section{THE MIDBRAIN 5-HTergic SYSTEM}

TOPOGRAPHICAL ORGANIZATION OF THE MIDBRAIN DORSAL RAPHE NUCLEUS AND THE CONTROL OF THE 5-HTERGIC NEUROTRANSMISSION

5-HTergic neurons of the midbrain raphe constitute a small group of multipolar cells that are distributed in the midline of the brainstem wherein are particularly located the median (MRN) and dorsal raphe (DRN) nuclei (Azmitia and Segal 1978, Parent et al. 1981, Azmitia 2001, Abrams et al. 2004). For the context of this work we will refer to DRN that is the most prominent of the 5HTergic nuclei from the midbrain. The DRN is situated in the ventral part of the periaqueductal gray matter of midbrain, extending caudally until the rostral portion of the pons. The 5-HTergic neurons of DRN are organized in clustered cells, in several topographical subdivisions. Among them, the rostral ventromedial area is the one that possesses contingent of cells that project towards forebrain sites implicated with the hydroelectrolyte and cardiovascular regulation (Azmitia and Segal 1978, Bosler and Descarries 1988, Jacobs and Azmitia 1992, Azmitia 2001). The ascending projections of DRN are arranged in ubiquitous way in connection to an extensive collaborative distribution in the terminal fields (Azmitia 1987, 2001). According to Azmitia conception, multiple subsets of 5-HTergic neurons participate of the integrated coordination of different control systems, e.g., autonomic, neuroendocrine and behavioral (Azmitia 1987, 2001, Jacobs and Azmitia 1992). This understanding has been resettled in recent report. Electrophysiological study shows that different subtypes of 5-HTergic neurons are implied on exclusive behavioral patterns. This observation allowed to postulate the hypothesis that subpopulation of 5-HTergic neurons topographically or- 
ganized would contain exclusive functional properties associated with the modulation of specific forebrain systems (Abrams et al. 2004).

5-HTergic neurons synthesize serotonin (5-HT) from the amino acid tryptophan (Azmitia 1987, 2001, Tyce 1990, Boadle-Biber 1993). 5-HTergic transmission and subsequent synaptic 5-HT release take place according to a rhythmic pattern which is spontaneously generated and can be modulated by a somatodendritic auto-feedback (Aghajanian et al. 1987, Azmitia 1987, 2001). This fine system of modulation is mediated through the activation of 5-HT1A somatodendritic autoreceptors (SDAR). 5-HT action on this receptor evokes a decrease of the neuronal firing rate and subsequent decrease of the 5-HT turnover. Therefore, the 5-HT concentration in the somatodendritic synapse increases. A proportional decrease on its release in the terminal fields of the ascending 5-HTergic neurons of DRN takes place (Sprouse and Aghajanian 1987, Hutson et al. 1989, Invernizzi et al. 1991).

FOREBRAIN STRUCTURES INVOLVED WITH THE HYDROELECTROLYTE REGULATION ARE INNERVATED BY ASCENDING 5-HTERGIC NEURONS FROM THE DRN

Especially the DRN contains subsets of 5-HTergic neurons which projects toward forebrain areas related to regulation of the electrolyte composition, ECF volume, as well as cardiovascular response (Azmitia and Segal 1978, Bosler and Decarries 1988, Azmitia 2001). Among them, the lateral hypothalamic area (AHL), SFO, OVLT, MnPOd, MnPOv, PVN and SON are the more prominently innervated by 5-HTergic neurons. Neurons that produce 5-HT constitute the first neuronal system to innervate the primordial cortical plate. 5HTergic neurons of the midbrain represent cellular group among the first neurons to undergo differentiation in the brain and to play a key role in the neurogenesis (Azmitia 2001). 5-HTergic neurons interact with multiple cellular types and subtypes of receptors (Azmitia 1987, 2001, Hoyer et al. 2002). Furthermore, the ubiquitous distribution of terminals and the diversity of forebrain 5-HT receptors has allowed to elaborate the hypothesis that 5-HTergic system would interfere practically in all of the integrative mechanisms of neuronal plasticity, in nature, autonomic, neuroendocrine, behavioral and cog- nitive (Azmitia and Segal 1978, Azmitia 1987, 2001, Jacobs and Azmitia 1992).

FOREBRAIN STRUCTURES INVOLVED WITH THE HYDROELECTROLYTE REGULATION INTERACT RECIPROCALLY WITH THE MIDBRAIN 5-HTERGIC NEURONS: BIDIRECTIONAL CIRCUITS SFO-DRN-SFO

Forebrain structures involved with the hydroelectrolyte and cardiocirculatory control reciprocally innervate the midbrain raphe (Lind 1986, Tanaka et al. 1998, 2001, Celada et al. 2002). Contingent of ANG II-sensitive neurons from SFO project toward 5-HTergic neurons of DRN (Tanaka et al. 1998). This assessment was carried out in study in which neurons of DRN, antidromically identified, were excited by intra-carotid or iontophoretic administration of ANG II into SFO. The authors concluded that ANG II-sensitive neurons from the SFO monitor the ANG II circulating levels and then transmit this information toward DRN. This same group demonstrated that hemorrhage (during which there is an increase of plasma ANG II levels) excites 5-HTergic neurons from the DRN which project fibers toward SFO, where an increase of 5-HT turnover was further detected (Tanaka et al. 2001). As such, increasing plasma ANG II levels also reflect the decrease in the ECF volume raised by the hyponatremia and it is plausible, additionally, to admit that circulating volume restoration is correlated with alterations on the DRN 5-HT turnover. In this context, multiple subtypes of 5-HT receptors, e.g., 5-HT1A, 5-HT2A, and 5-HT2C were pharmacologically identified in SFO (Scrogin et al. 1998). In this study, the authors reasoned that 5-HT release in SFO could be related to the control of vasopressin secretion. However, considering the role of SFO in the sodium appetite expression and AT1 receptors identification over there, the hypothesis of 5-HTergic transmission in this structure to influence the angiotensinergic activity must not be excluded. Tanaka's group has evidenced through the microdialysis that microinjection of ANG II into SFO reduces the extracellular 5-HT and its metabolites levels (Tanaka et al. 2004).

Moreover, a possible feed-back loop between SFO and raphe is plausible. This assertive is based on observation of ANG II-binding sites and AT1 receptors identified in the DRN (Song et al. 1992, Moulik et al. 
2002). It is possible an interaction between blood borne ANP or synaptically ANP released at DRN. Experimental changes in water and salt homeostasis influence the levels of ANP in the DRN (Palkovits et al. 1990). A significant decrease of ANP levels was detected in the DRN after the development of hypertension in SHR rats in comparison to normotensive controls (Bahner et al. 1988).

These demonstrations reinforce the possibility that these forebrain and midbrain structures reciprocally relay information during homeostatic challenges for the regulation of the water and salt ingestion and cardiocirculatory adjustment as glimpsed by Lind (Lind 1986).

Taken together, these observations above constitute circumstantial evidences of the existence of a neuronal circuit SFO-DRN-SFO that must be implicated in the regulation of hydroelectrolytic and cardiovascular balance as previously proposed (Lind 1986, Reis et al. 1994, Cavalcante-Lima et al. 2005a, b). Additionally, it should not be ruled out the possibility of other reciprocal interactions between forebrain areas and midbrain raphe, particularly among OVLT, MnPO and AHL and DRN. These speculations from the experimental observations performed by Tanaka, raise the possibility that other humoral signals (e.g., plasma levels of ANP and OT) as well as the neural release of these peptides in structures of the lamina terminalis, integrate monitoring systems of the hydroelectrolytic status.

The neuroanatomical relationship mentioned before presuppose the elaboration of complex functional interactions between forebrain and midbrain structures. It may concern the control of autonomic, neuroendocrine and behavioral functions during homeostatic challenges presented by environment.

\section{5-HTergic SYSTEM AND RENAL SODIUM EXCRETION REGULATION}

EXPERIMENTAL APPROACHES OF THE 5-HTERGIC SYSTEM

To evaluate the role of 5-HTergic system in the renal sodium excretion regulation several experimental approaches has been used. A first approach has been attained through the icv administration of 5-HT and, 5HT1A, 5-HT2 and 5-HT3 receptor agonists. In these conditions, microinjections are performed through the guide cannula implanted in the $\mathrm{AV} 3 \mathrm{~V}$ region or in the lateral ventricle. In a second condition, electrolytic lesions of the raphe were made through the passage of anodal current by electrodes estereotaxically directed to DRN. In a third approach, the icv or peripheral pchloro-phenyl-alanine (pCPA) administration has been performed. This modified amino acid inhibits the tryptophan-hydroxylase (TPH) in an irreversible way. TPH is the limiting enzyme of the 5-HT synthesis (Tyce 1990). Accordingly, this procedure produces a depletion of brain 5-HT, in such a way that 5-HTergic transmission restoration takes place just some days after the injection, subsequently to de novo synthesis of TPH (Chaput et al. 1990, Lima et al. 2004). In the protocol suggested by Chaput and colleagues, pCPA administration (350 mg/kg, ip, for two days) induces a depletion of more than $90 \%$ of brain 5-HT, decreasing drastically the turnover of the indoleamine and the effectiveness of the 5-HTergic transmission (Chaput et al. 1990).

\section{5-HT2 AND 5-HT1A AGONISTS AND RENAL SODIUM EXCRETION}

5-HT and 5-HT2 receptor agonists, MK212 and DOI, administered in the $\mathrm{AV} 3 \mathrm{~V}$ region increased the urinary sodium excretion in rats hydrated by intra-gastric load. Previous icv administration of LY53857, a 5-HT2C antagonist, abolished the natriuretic response induced by 5-HT, MK212 and DOI. This observation allowed us to raise the hypothesis of involvement of the activation of 5-HT2C receptors in the central mediation of sodium excretory response (Reis et al. 1991a). The time course of natriuretic response simultaneously evolved to a kaliuresis and transitory antidiuresis. In contrast, icv administration of the 5-HT1A receptor agonist, 8-hydroxidi-propil-amino-tetraline (8-OH-DPAT) induced antinatriuretic and antikaliuretic responses, simultaneously to transitory antidiuresis (Reis et al. 1991a). This provided the hypothesis that excitatory 5-HT2C mechanism related to sodium excretion is modulated by 5 -HT1A postsynaptic activation. Similar results were reached in another study with hydrated rats by intravenous administration of hypotonic saline. In this model, icv 5-HT administration induced an increase of the urinary sodium excretion. The authors attributed the 5-HT natriuretic response to the decrease in the electric renal nerve activity (Montes and Johnson 1990). 
Probably other central postsynaptic 5-HT receptor mechanisms are involved with the renal sodium excretion, considering the diversity of 5-HTergic pathways concerning the sodium appetite control (see below). In another study, it was shown that kainic acid-induced MRN stimulation, and systemic tryptophan overload significantly increased sodium excretion in hydrated rats (Reis et al. 1991b). It concluded that both responses reflect an increased 5-HTergic synaptic transmission.

Taken together, observations from different groups provided evidence that 5 -HTergic system regulates the renal electrolyte excretion through the 5-HT2 and 5HT1A receptors activation. It remains to be explained the way by which different postsynaptic 5-HTergic receptor mechanisms operate the coordination of the hydroelectrolytic balance. Likewise, the efferent pathway responsible by the action on the renal targets also remains to be elucidated.

LESIONS OF THE MIDBRAIN RAPHE NUCLEI, BRAIN 5-HT DEPLETION AND SODIUM EXCRETION

The electrolytic lesion of MRN and of DRN induced an antinatriuresis in hydrated rats without significant alteration in the potassium excretion response and diuresis (Reis et al. 1994). Decrease of the urinary sodium excretion is maintained for four days after the lesion. The antinatriuretic response was more intense in the DRN- than in MRN-lesioned rats. Antinatriuresis in DRN-lesioned rats correlated with a drastic reduction of the ANP plasma levels, in basal conditions and after blood volume expansion. At the end of one week the DRN-lesioned rats recovered the normal values of sodium excretion as well as the ANP plasma levels. The brain 5-HT depletion reached by icv pCPA administration, in similar way, evoked a reduction of the sodium urinary excretion. Antinatriuretic response was expressed at three and seven days after the pCPA central injection. Two weeks after the central injection the sodium excretion was recovered at the normal levels. Additionally, 5-HT-depleted rats presented lower levels of ANP in basal conditions and during blood volume expansion, as well. These observations raised the hypothesis that DRN neurons, putatively 5-HTergic, regulate the sodium renal excretion through the control of the ANP release (Reis et al. 1994).

\section{THE ROLE OF THE 5-HTergic SYSTEM IN THE SODIUM APPETITE AND THIRST REGULATION}

\section{5-HT RELEASER OR 5-HT1A AND 5-HT2/3 RECEPTOR AGONISTS AND SODIUM APPETITE}

The first indirect evaluations concerning the influence of the 5-HTergic system on the sodium appetite were carried out in rats systemically treated with 5-HTergic agents (e.g., 5-HT agonists, 5-HT releaser or 5-HT pre-synaptic uptake inhibitor). Thus, an acute peripheral administration of the 5-HT2C agonists, MK212 and mCPP, 5HT releaser, fenfluramine or 5-HT pre-synaptic inhibitor, fluoxetine, reduced selectively the consumption of hypertonic saline in the dehydrated-rats (Neill and Cooper 1989). Conversely, small doses of 5-HT1A agonists, 8OH-DPAT and gepirone systemically administered increased the hypertonic saline ingestion in rehydrating rats, in test of 30 minutes, with no effect in the water ingestion (Cooper et al. 1988). Similar reports were obtained from observations done in sodium-depleted rats and treated with dexfenfluramine, a brain 5-HT releaser, and metergoline, a 5-HT2 antagonist (Rouah-Rosilio et al. 1994). In this study, it was demonstrated that dexfenfluramine administration reduced drastically the $3 \%$ $\mathrm{NaCl}$ ingestion in sodium-depleted rats, as well as, the spontaneous $1.8 \% \mathrm{NaCl}$ consumption, with no effect in water ingestion. Additionally, it was evidenced that metergoline administration increased the ingestion of hypertonic saline in need-free conditions in rats with either a history of three previous depletions or not. According to Rouah-Rosilio et al. (1994) these data support the hypothesis that 5-HTergic system transmission exerts a tonic inhibition of the salt intake. Studies carried out in our laboratory led to similar results. Acute systemic treatments with the brain 5-HT releaser, fenfluramine, the selective 5-HT re-uptake inhibitor, fluoxetine or the 5-HT2C receptor agonists, MK212 and mCPP, reduced significantly the hypertonic saline ingestion, in both, fluids and food deprived-rats and sodium-depleted rats as well (Badauê-Passos et al. 2003). Intracerebroventricular administration of 5-HT agonists confirmed the observations obtained with the systemic treatment and introduced the probable participation of another 5-HT receptor. Thus, central stimulation of 5-HT2C and 5-HT3 receptors, through the icv microinjection of $\mathrm{mCPP}$ and $\mathrm{m}-\mathrm{CPBG}$, respectively, inhibited the hypertonic saline 
ingestion in sodium depleted-rats (Castro et al. 2003). Following these results, it has been admitted the hypothesis that 5-HTergic system participates in the sodium appetite regulation,

(i) after the sodium depletion, inhibiting the needinduced salt ingestion, and

(ii) in basal conditions, inhibiting need-free salt ingestion.

On the other hand, Cooper and Ciccocioppo (1993) showed that acute administration of 5-HTergic 5-HT1A agonists, ipsapirone, gepirone, and 8-hydroxy-2-(di-npropylamino) tetralin (8-OH-DPAT) induced to an increased salt intake in two-choice tests in water-deprived rats. The authors assumed these results as a consequence of inhibitory action of 5-HT1A agonists at SDAR, which leads to reduction of the central 5-HTergic activity. Recent studies in our laboratory have shown in opposed way that chronic treatment with 8-OH-DPAT decreased the salt intake in sodium-depleted rats (D. BadauêPassos et al., unpublished data). This result possibly elapses from desensitization of SDAR produced by its chronic exposition to 5-HT1A agonist as demonstrated elsewhere (Blier and de Montigny 1990, Haddjeri et al. 1999).

\section{BRAIN 5-HT DEPLETION AND LESION OF DRN INCREASE THE HYPERTONIC SALINE INGESTION IN BASAL CONDITION AND AFTER HYDROELECTROLYTIC CHALLENGES}

To evaluate the participation of 5-HTergic pathways on the modulation of the sodium appetite, two experimental models were used by our group:

(i) brain 5-HT depletion, through the systemic administration of pCPA (350 mg/kg, for 2 days, ip); and

(ii) electrolytic or excitotoxic lesion of DRN.

The reduction of the brain 5-HT content drastically potentiated the natriorexigenic response evoked by the sodium depletion in furosemide treated rats (Lima et al. 2004). Interestingly, the exaggerated sodium appetite response occurred three days after the pCPA administration. In contrast, seven days after pCPA treatment, the natriorexigenic response became lower than control values, probably due to the overexpression of TPH or elevated 5-HT transporter mRNA levels, such as suggested elsewhere (Cooper et al. 1996, Rattray et al. 1996). Two weeks after sodium appetite response returned to basal values.

These results raised the hypothesis that transitory 5-HT depletion activates the cycle of 5-HT restoration whose evolution influences the salt ingestion behavior under hyponatremic and hypovolemic conditions. The high capacity of natriorexigenic modulation one week after pCPA administration would constitute a reaction of plasticity of the 5-HTergic neurons that would acquire the properties of de novo synthesis, of increasing 5-HT turnover and ascending transmission, as well.

Peripheral administration of isoproterenol (a potent dipsogenic agent, which acts through renin releasing and hypotension stimuli) in pCPA-treated rats, induced intense water and hypertonic saline ingestions, while in the controls it was just observed the classic dipsogenic response (Lima et al. 2004). Electrolytic lesions of the ventromedial portion of DRN induced an increase of the hypertonic saline ingestion, in basal condition. However these experimental procedures were performed for three days. Water ingestion was also more intense from the $3^{\text {rd }}$ hour up to the $12^{\text {th }}$ hour post-lesion, when it became equal to control values until the $3^{\text {rd }}$ day of the experiment (Olivares et al. 2003). DRN-lesioned rats displayed more intense dipsogenic and natriorexigenic responses provoked by the furosemide + low captopril dose association.

These observations provided the conclusion that DRN electrolytic lesion suppresses an ascending inhibitory activity of the sodium appetite. The electrolytic lesions selected for the study, were limited to the ventral-medial area of DRN where there is an expressive contingent of 5-HTergic perikarya which project to the forebrain. However, in this procedure the passage axonal fibers and non-5-HTergic neurons were also damaged. For this reason, subsequent studies were undertaken to circumscribe the lesion just to the perikarya located in the dorsal-ventral-medial subregion of DRN through the microinjection of the excitatory amino acid, ibotenic acid. Excitotoxic lesions of DRN produced qualitatively the same responses reached with the electrolytic lesion and the brain 5-HT depletion, rendering the interpretations more accurate concerning the involve- 
ment of genuine neurons of this structure (CavalcanteLima et al. 2005a, b). Ibotenic lesions of DRN induced an increase of the basal hypertonic saline ingestion that began in the $3^{\text {rd }}$ day of the ibotenic acid injection and was maintained in $20 \mathrm{ml}$ plateau from the $11^{\text {th }}$ day, for several days. Water ingestion was not significantly altered; therefore, the preference for sodium was sustained in high values during the whole period of observation. When DRN-lesioned rats DRN (21 and 35 days intraDRN post-injection) were deprived of fluids and food, an intense hypertonic saline ingestion was observed while the dipsogenic response was comparable to the controls.

The dipsogenic response evoked by isoproterenol, showed that the lesioned rats $(7,21$ and 35 days after ibotenic lesion) presented a higher sodium appetite, while the water ingestion was comparable to the controls. High cumulative hypertonic saline ingestion was maintained for a long period until the $2^{\text {nd }}$ day of observation, while control values were sustained within low levels during the whole period. Similar results were obtained with the subcutaneous administration of polyethylene glicol, PEG. Coloidosmotic action of PEG evokes a hypovolemia associated to extracellular dehydration. In this condition, the DRN-lesioned rats (21 days after ibotenic acid injection) exhibited a more precocious and intense sodium appetite than the controls. Dipsogenic response was developed just like in the control group, but it was higher after 5 hours elapsed from the fluids presentation. On the other hand, lesioned and sodium depleted-rats exhibited an association between an intense natriorexigenic response and a larger water intake when compared to the controls.

Chronic treatment with low dose of captopril ( $1 \mathrm{mg} / \mathrm{g}$ of chow), similarly to captopril added to water, increases plasma ANG I levels due to the action on peripheral but not on the central ACE (Fitzsimons 1998). This condition induces a suppression of the negative feedback in the juxtaglomerular cells, and a subsequent, hyperreninemia and low ANG II plasma levels. Thus, a high brain availability of ANG I, affords an increase of its central conversion to ANG II, particularly in SFO. It results of this context an increase of the sodium appetite. In this paradigm, lesioned-rats at six days after ibotenic acid injection, which had already exhibited a higher hypertonic saline consumption additionally, increased the sodium appetite. Twenty-four hours after captopril removal from the diet, the hypertonic saline consumption was lower than the pretreatment levels. Water ingestion practically did not differ between the groups. In the groups of lesioned rats (21-35 days post-lesion) 48 hours after the end of the experimental observations, more than $50 \%$ of them mouthed and bit a crystal of $\mathrm{NaCl}$ offered in the tip of the tweezers (representative picture in Figure 1).

Taken together, results obtained from brain 5-HT depletion and electrolytic or excitotoxic lesion of DRN, disclosed a high sensitivity of the brain to experimental paradigms that evoke increases on plasma ANG II levels or central angiotensinergic activity. This observation allowed us to suspect that deficit in the 5-HTergic ascending transmission represents the suppression of an important modulatory pathway of the sodium appetite. It is tempting to compare our experimental model, at least partially, with the functional condition of the spontaneously hypertensive rats (SHR). SHR rats develop an intense sodium appetite associated with increased angiotensinergic sensitivity in forebrain loci related with the cardiocirculatory and hydroelectrolytic homeostasis (Stocker et al. 2003). It is noteworthy that these alterations have been concomitant with a deficit in the 5-HT turnover in forebrain sites. Alternatively, ascending the 5-HTergic pathways would constitute a modulatory system involved in the control of the ANP release. The first favorable indirect observation of this postulation was made in work in which we demonstrated that 5HT brain depletion and the DRN lesion induce a deficit of the plasma ANP levels, in basal conditions, or after blood volume expansion (Reis et al. 1994). This can be considered the predisposing factor of the increased sodium appetite developed in the 5-HT-depleted or DRNlesioned-rats. An objection can be raised against this hypothesis. One to two weeks after the experimental procedures, the rats have recovered the capacity to regulate sodium excretion. Nevertheless, more recent studies (Cavalcante-Lima et al. 2005a, b) evidenced that an intense sodium appetite persisted for a long period (up two weeks, at least) in DRN excitotoxic lesioned-rats. Then, other modulatory systems could be involved. One of them might be represented by OT action in the SFO. Original studies of the Stricker's group showed the in- 


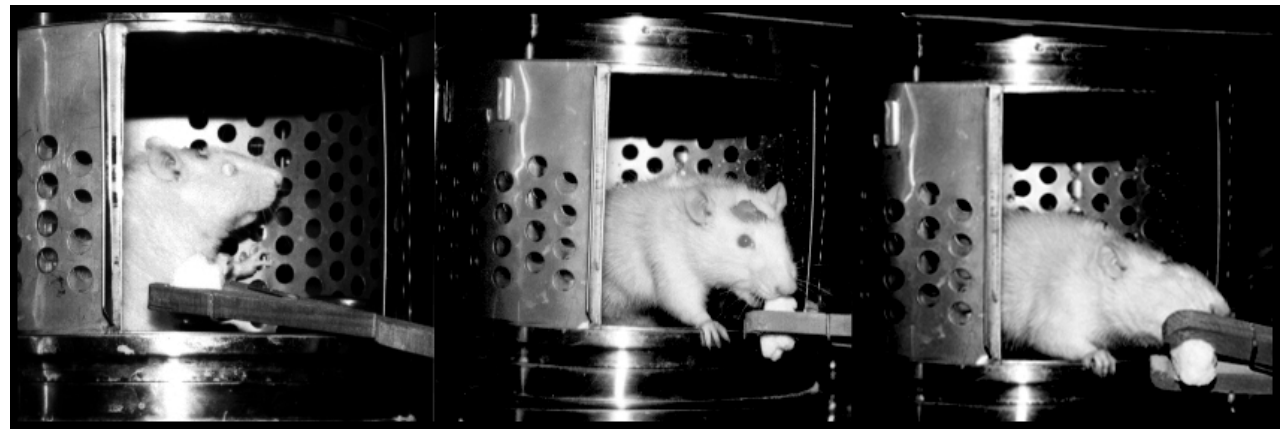

Fig. 1 - Pictures of a rat inside the metabolic cage which it is receiving a $\mathrm{NaCl}$ crystal in the tip of a tweezers. The rat depicted in this sequence of pictures is representative of group that exhibited intense sodium appetite at 35 days elapsed from the micro-injection of ibotenic acid into dorsal raphe nucleus (which has been for the first time demonstrated by our laboratory). It is observed the visual, olfactory and gustatory detection and recognition following by the mouthing and bite of crystal of $\mathrm{NaCl}$.

hibitory role of OT on the sodium appetite (Blackburn et al. 1995, Stricker and Verbalis 1996). This homeostatic system would be responsible by ECF volume adjustments (see above) through an increase of renal sodium excretion and a decrease in salt ingestion (Soares et al. 1999, Antunes-Rodrigues et al. 2004). Immunoreactivity studies for Fos protein showed that neurons of DRN, area postrema (AP) and LPBN and also the magnocellular portion of PVN, particularly the OT producing neurons, are intensely labeled, in sodium depleted rats with free access to hypertonic saline (Franchini and Vivas 1995, Franchini et al. 2002). This subregion is densely innervated for 5-HTergic fibers projected from DRN and thus the 5-HT stimulation induces an increase of OT releasing (Azmitia and Segal 1978, Saydoff et al. 1991, Jorgensen et al. 2003). Therefore, the role of 5-HTergic system in sodium appetite may involve the oxytocinergic neurons stimulation in a non-identified physiological context yet.

Recent evidence of Hiyama et al. (2004) showed that the SFO is the primary site of the Na-level sensing associated with the salt intake. In this paper the authors discovered that a specialized voltage-dependent sodium channel constitute a $\mathrm{Na}_{\mathrm{x}}^{+}$channel sensing mechanism implied with the salt-avoiding behavior in dehydrated rats. Noteworthy is that such mechanism operates under an independent way comparatively to sodium appetite mechanism induced by ANG II within the SFO. Lesions of the DRN or brain 5-HT depletion potentiate the sodium appetite induced by multiple paradigms, including dehydration. Therefore, intact ascending 5-HTergic pathways may also modulate (exciting) the salt-avoiding behavior under dehydrating, and possibly other conditions related to sodium depletion (inhibiting).

BRAIN 5-HTERGIC SYSTEM MODULATES THIRST AND WATER INTAKE

In addition to sodium appetite control, 5-HTertic system is involved with the thirst and water intake regulation. Icv injection of MK212, a 5-HT2C agonist, induced to inhibition of water intake after water deprivation or central cholinergic, ANG II and beta-adrenergic stimulation (Reis et al. 1990a, b, 1992). In opposed way, we demonstrated in another study that electrolytic lesion of DRN, induced an intense dipsogenic response in rats with access only to water (Reis et al. 1994). In both conditions, after central 5-HT agonist injection or lesion of DRN, the rats had free access just to water.

SALT INTAKE INCREASES THE FOS PROTEIN EXPRESSION 5-HTERGIC NEURONS OF DRN AND CONCOMITANTLY INTO THE AP AND LPBN

Accordant evidences to hypothesis that 5-HTergic neurons participate in the sodium appetite modulation were obtained in experimental model in which the immunoreactivity technique was used for the Fos protein determination aiming to map the neuronal population activated after the salt ingestion (Franchini et al. 2002). In 
order to induce sodium appetite, a peritoneal dialysis method was used. To identify the 5-HTergic neurons an immunocytochemistry technique for 5-HT labeling was performed. Fos protein immunoreactive increased significantly in 5-HTergic neurons of the DRN after spontaneous or induced hypertonic saline ingestion in rats with free access to the fluids. Fos protein labeling was increased in neurons with perykaria in the AP and LPBN. $\mathrm{AP}$ is a structure that measures alterations in the plasma and cerebrospinal fluid (CSF) and sends projections for LPBN. In integrative means, LPBN interacts reciprocally with DRN and receives afferents of NTS transmitters of visceral sensory information concerning alterations in the volume and ECF electrolyte composition (Petrov et al. 1992a, b). This postulation was recently reassessed in an article, in which it was demonstrated that hypertonic saline and water ingestion increase significantly 5-HT and 5-HIAA levels in LPBN (Tanaka et al. 2004). On the other hand, the combined treatment of furosemide + low dose of captopril evoked a reduction in the 5-HT and 5-HIAA concentration in LPBN.

Neuro-anatomical evidences joined to physiological observations of Franchini and Tanaka, and their collaborators allow us to impute to the LPBN, AP and DRN a neuroanatomical source of the sodium appetite and ECF volume control in the same homeostatic context.

\section{5-HT MECHANISMS IN LPBN AND REGULATION OF THE SODIUM APPETITE}

LPBN is an important pontine circuit involved in the regulation of the sodium appetite (Menani et al. 1996, 1998a, b). The more dense afferent fibers to LPBN are arisen from AP and NTS. Therefore, LPBN receives visceral sensory signals which converge toward NTS. In addition, visceral signaling and plasma and CFS information are integrated in the AP. A particular contingent of neurons that arise in AP and NTS is producer of 5-HT, nevertheless they do not represent classical 5-HTergic neurons as those of the midline of the brainstem (Azmitia and Segal 1978, Parent et al. 1981, Azmitia 1987, Franchini et al. 2002). Group of fibers that project from DRN which constitute the efferent innervation of LPBN, is composed by typical 5-HTergic and non-5-HTergic neurons (Petrov et al. 1992a, b). On the other hand, LPBN sends peptidergic fibers toward DRN. Therefore, many studies show that 5-HTergic input to LPBN is relevant to specific sodium appetite control (Menani et al. 1996, Johnson and Thunhorst 1997, McKinley and Johnson 2004). This important role attributed to LPBN is partially consequence of its strategic relay position, which permits an exchange of information with other relevant nuclei as DRN, AP and NTS as well. Bilateral administration of 5-HT1/2 antagonist, methysergide or 5HT2A/2C agonist, DOI, in LPBN influences the sodium appetite raised by several experimental paradigms. Increase of the hypertonic saline ingestion provoked by the ANG II icv micro-injection or the furosemide + captopril sc injection was increased by the intra-LPBN administration of 5-HT1/2 antagonist.

By contrast, administration of DOI in LPBN decreased the hypertonic saline ingestion induced by the furosemide + captopril (Menani et al. 1996). Similar results were obtained in models of salt ingestion induced by DOCA, water deprivation, sodium depletion or, betaadrenergic stimulation (Menani et al. 1998a, De Gobbi et al. 2000). These authors demonstrated that AT1 antagonist, losartan, administrated into SFO reduced the additional salt ingestion raised by the blockade of LPBN 5-HT1/2 receptors in rats treated with the furosemide + captopril association (Colombari et al. 1996, Menani et al. 1998b). Additionally, it was evidenced that cholinergic stimulation through the icv carbachol microinjection, that classically evokes dipsogenic response, induced an intense hypertonic saline ingestion after blockade of LPBN 5-HT1/2 receptors (Menani et al. 2002).

These observations clearly showed the functional role of LPBN where are located an inhibitory 5-HTergic mechanism of the sodium appetite (Menani et al. 1996, McKinley and Johnson 2004). As above examined, LPBN is part of an inhibitory coordination system of the sodium appetite at which would also incorporate AP and DRN for the integrative control of salt ingestion.

\section{CLINICAL CORRELATIONS}

\section{EXCESSIVE SALT CONSUMPTION}

The consumption of salt has been increased in Western populations, for cultural habits, particularly incited by "salt appeal" paralleled to publicity of fast-food and elaborated meals. In an opposite side, the Ianomamo, 
indigenous of the Brazilian Amazonia, ingest less than $0.5 \mathrm{~g}$ of $\mathrm{NaCl} / \mathrm{day}$ while, especially in the great metropolitan centers, other individuals consume close to $30 \mathrm{~g}$ /day (personal communication from J.J. Kenney about your advertising article, "Salt toxicity: Is it a major threat to public health?" (Detail in www.foodandhealth.com/cpecourse/salt.php). This is probably due to the fact that the increasing use of salt has provided the development of hedonistic repertoire during the feed behavior. Contemporarily, the feed became more and more elaborated in function of the organoleptic properties of the meals, including pet food. Possibly the habit acquisition of excessive salt consumption among the human beings has influenced the expression of this behavior in domestic animals.

The first consistent physiological evidence that exaggerated salt consumption can contribute to the development of hypertension was obtained from the observations of Denton and colleagues (Denton et al. 1995). These authors showed that $\mathrm{NaCl}$ addition to the natural diet of a colony of chimpanzees, in a similar proportion to typical North American diet (>10 g/day) induced an elevation of the blood pressure for more than 20 months of observation. The salt removal of the diet promoted a decline of the blood pressure just after 6 months. A positive correlation was established among consumption of salt by several ethnic groups and the development of systolic hypertension (J.J. Kenney, personal communication). While Ianomamo maintain systolic pressure (PS) in a range of $100-110 \mathrm{~mm} \mathrm{Hg}$, from 20 to 69 years age, other ethnic groups, as the North Americans and part of the Europeans present an increase of the PS that reaches 140-160 mm Hg. Overconsumption of $\mathrm{NaCl}$ takes place in more than $30 \%$ of the U.S. population which are genetically predisposed to manifest hypertension (Daniels and Fluharty 2004). However, it should be considered the fact that there are populations which consume excessive amounts of $\mathrm{NaCl}$ but present resistance to the development of the hypertension like the Eskimo and Masai.

Therefore, in view of the epidemiological data concerning the excessive salt consumption and its correlation with the hypertension, the studies of the regulatory mechanisms of the sodium appetite and their motivational components, have attracted increasing attention in the scientific investigation. Most of the studies have been dedicated to the research of mechanisms of homeostatic regulation of sodium appetite (need-induced, e.g., natriorexis) while less attention has been driven to the study of the hedonistic mechanisms of the salt ingestion (need-free, e.g., natriophylia) (Fitzsimons 1998).

According to Daniels and Fluharty's viewpoint the overconsumption of $\mathrm{NaCl}$ in most developed societies represents an example of homeostatic regulation that didn't resist to societal and cultural practices, e.g., hedonistic habits (Daniels and Fluharty 2004).

\section{HYPERTENSION}

The association between the reduction of the brain 5HTergic transmission and hypertension was performed in an article, which investigated if the tonic 5-HTergic activity is related to the variability of rest blood pressure in human beings (Muldoon et al. 1998). To evaluate the brain 5-HTergic activity the authors used a neuroendocrine approach, which determined the prolactin secretory capacity through the fenfluramine administration, a 5-HT releaser. In this study, it was evidenced that prolactin liberation induced by fenfluramine was correlated inversely with the blood pressure, in white Caucasian individuals suggesting a role of the central 5HTergic system in the pathogeny of hypertension. The same authors demonstrated a lower prolactin secretory response in SHR rats injected with fenfluramine (Stocker et al. 2003).

In a contextualizing to the background of the present review, it is interesting to report the coexistence of increased angiotensinergic activity and the deficit in the 5-HTergic transmission in forebrain loci, in SHR rats parallel to the chronic hypertension and the increased sodium appetite (see above).

\section{STRESS AND AFFeCTIVE DisORDERS}

5-HTergic neurons in the DRN are mediators of neuroendocrine and behavioral response to stressor conditions (Graeff et al. 1997, Maier and Watkins 1998, Chaouloff 2000, Lowry 2002). In this context, the intra-DRN administration of CRF1 agonist inhibits 5-HTergic activity whereas CRF2 agonist increases the 5-HT efflux in the forebrain (Kirby et al. 2000, Amat et al. 2004). On the other hand, corticoid hormone administration, a maneu- 
ver that mimics stress condition, influences the TPH content in the brain. Acute treatment of adrenalectomized (ADX) rats with the glucocorticoid, dexamethasone, induced an increase in the raphe TPH mRNA levels (Azmitia et al. 1993). Conversely, following chronic treatment of $\mathrm{ADX}$ rats with dexamethasone for one week there was strong decrease in TPH mRNA levels in the DRN (Clark and Russo 1997). This last finding constitutes important evidence that chronic stress affords to reduce the 5-HT turnover in the forebrain loci. It is tempting to conjecture what chronic stress leads to 5-HT midbrain depletion and 5-HTergic hypofunction with subsequent reverberation in the sodium appetite threshold.

Among the affective disorders, the depression can coexist with the development of cardiocirculatory disturbances (Braszko et al. 2003). In this condition it is frequent the diagnosis of 5-HTergic hypofunction performed through the proof of the capacity of prolactin release after administration of 5-HT releaser (Meltzer and Lowy 1987). In this meaning, tryptophan and 5-HT depletion is a paradigm broadly employed in the study of the mechanisms related to 5-HTergic system and to development of the depression (Neumeister 2003, Elhwuegi 2004, O'Reardon et al. 2004). It is compelling to speculate that conflicts during the interaction with the environment might generate disturbances in the regulation of the ECF volume and of blood pressure. These homeostatic perturbations would be related with the deficit in the 5-HTergic transmission toward forebrain and hindbrain sites implicated with the autonomic, neuroendocrine and behavioral control of cardiocirculatory and hydroelectrolyte balance.

In this context, some reports have shown that depressive patients frequently develop hypertension (Braszko et al. 2003). On the other hand, in model of brain 5-HT depletion through both the pCPA ip administration and the DRN lesion, we demonstrated the expression of an exaggerated natriorexigenic response after sodium depletion in rats (Olivares et al. 2003, Lima et al. 2004, Cavalcante-Lima et al. 2005a, b). However, there are no systematic clinical studies approaching the development of the excessive salt consumption and the hypertension incidence in depressed patients correlated with the deficit in the 5-HTergic activity.

\section{HYPOTHYROIDISM}

During the development of the experimental hypothyroidism rats express an intense sodium appetite, partially attributed to hyponatremia induced by decrease of the RAAS activity (Taylor and Fregly 1964, Ventura et al. 2001, Badauê-Passos et al. 2001, 2003). In this sense, study of Belló and Covian correlated a spontaneous natriofilia with hypothyroidism incidence in offspring of rats in vivarium of a research institute. The reversion of the hypothyroidism through the treatment with thyroid hormone normalized the sodium appetite response (Belló and Covian 1988, 1991). The induction of hypothyroidism leads to alterations in the plasticity of brain monoamimergic systems, particularly, the development of 5-HTergic hypofunction (Vaccari 1982). Studies on the neuroendocrine mechanism of prolactin release in hypothyroid rats, showed that deficit of prolactin releasing is associated with brain 5-HTergic hypoactivity (Ramalho et al. 1990). Recently, our laboratory evidenced an increased sodium appetite in basal conditions and an exaggerated natriorexigenic response in hypothyroid rats evoked by several paradigms. Natriorexigenic response was weakened by the chronic administration of aldosterone and by acute treatment with 5 -HTergic agents. Chronic treatment with the AT1 antagonist, losartan also reduced, in a drastic way, the sodium intake response induced by low captopril dose added to the food, during the 2-4 days following the treatment in hypothyroid rats. However, the animals retook the hypertonic saline ingestion, in spite of the treatment maintenance with losartan on the 7 subsequent days, therefore, disclosing an alteration in the brain angiotensinergic sensitivity (Ventura et al. 2001, Badauê-Passos et al. 2003). Hypothyroid rats developed a reduction of the activity of peripheral RAAS therefore the intense sodium appetite is possibly resulting from association of the hypoaldosteronism with the 5-HTergic hypofunction. However, related studies are not known in hypothyroid patients concerning the alterations in the sodium appetite. Further, hypothyroid patients can develop depression, condition in which clinical correlations with the salt ingestion behavior are also unknown. In view of the more recent knowledge regarding the sodium sensing system in the SFO it remains to be elucidated how the hypothyroidism settle the mediation of this mechanism under oscillation of the brain 
sodium concentration and, to that extent, such alteration contributes for the sodium appetite response.

Gustatory disorder can also contribute for exacerbating sodium appetite in hypothyroidism. In this context, hypothyroid subjects manifest a diminished intensity perception for salt and thus, an increased pleasant response to sodium chloride (Bhatia et al. 1991). It is not yet known if putative 5-HTergic hypofunction during the hypothyroidism in human beings is involved in this anomalous sensory integration.

\section{CONCLUSIONS}

Neural projections from the 5-HTergic system are ubiquitously distributed in the encephalon during the ontogenetic development of the nervous system. Thus, according to Azmitia conception, literally all of the brain activities would be under the 5-HTergic influence, from the homeostatic levels, autonomic, neuroendocrine and behavioral to the cognitive functions. Therefore, in which it refers to regulation of the hydroelectrolytic balance it is possible that 5-HTergic activity extends to all levels of coordination of the brain function. While it regulates the electrolytes excretion through the control of the autonomic efferent activity for the renal tubules and through the ANP secretion, 5-HTergic circuit of DRN, possibly integrated to NPBL, it would be also responsible by stimulation of different mechanisms of sodium appetite inhibition.

Particularly, according to control of the salt satiety, the evidences reported here have converged for five possibilities. 1) 5-HT pathways would interact with ANPergic neurons of the lamina terminalis exciting the neural circuitry of sodium satiation after salt ingestion period. 2) The stimulation of the heart ANP release, by neuroendocrine mechanism, mediated by structures of the lamina terminalis, would also contribute for some context to modulate the sodium appetite. In this meaning, the ANPergic neurons would stimulate oxytocinergic neurons in the PVN to release oxytocin from the pituitary and neural synapses at SFO. 3) Similarly, ascending 5HTergic pathways would modulate the activity of ANG II-sensitive neurons of SFO implicated with the activation of excitatory circuits of the sodium appetite during the ECF repletion volume. 4) 5-HTergic neurons of the DRN would be indirectly implied in the modulation of the sodium appetite through the activation of oxytocinergic neurons which would be transmitters of inhibitory signals for the expression of this behavior. 5) After recent evidence in which $\mathrm{Na}_{\mathrm{x}}^{+}$channel sensing mechanism (Hiyama et al. 2002, 2004) are implied with the saltavoiding behavior it is tempting to postulate that the ascending 5-HT pathways can be also modulating the sodium appetite under dehydrating and possibly other conditions related to sodium depletion.

Until this moment, there is no substantial knowledge, which demonstrated the involvement of the 5HTergic system in the control of the detection and recognizing of salty taste. In just one study, the taste recognizing and perception were evaluated through four primary gustatory sensations (e.g., sweet, bitter, salty and sour) in patients with seasonal affective disorder (SAD) (Arbisi et al. 1996). In this condition usually it expresses an increased appetite associated with carbohydrate craving that are characteristic symptoms of SAD and imputed to the decreasing in central 5-HTergic function (Wurtman and Wurtman 1989). It concluded that the arrival of the winter exerted significant effects on the sweet, bitter and sour detection but it didn't influence the salty detection thresholds. Several aspects remain to be elucidated, among which, how SAD patients would behave in view of volume depletion paradigms and hyponatremia in what concerns detection of salty taste.

In attempting to visualize the anatomical and functional substrata of these hypothesis, it is depicted in Figure 2 the relationship among visceral sensory stimuli (volume depletion, decrease of the sodium filtered load along of macula densa, etc), plasma levels of ANG II, ANP, OT and the activation of ascending 5-HTergic pathways. After incitement by ultimate proof of the sodium sensing mechanism in the SFO we also included it in Figure 2. Reciprocal relationships between SFO and DRN and between DRN and NPBL are also represented aiming to show the plasticity of the adaptive behavioral reactions induced by the volume depletion through the (i) signaling from the visceral sensory challenges and (ii) monitoring of plasma levels of ANG II, ANP and OT performed by forebrain structures.

It would still remain to investigate the physiological context in that each one of those homeostatic mechanisms participates. And then, if collaborative mech- 


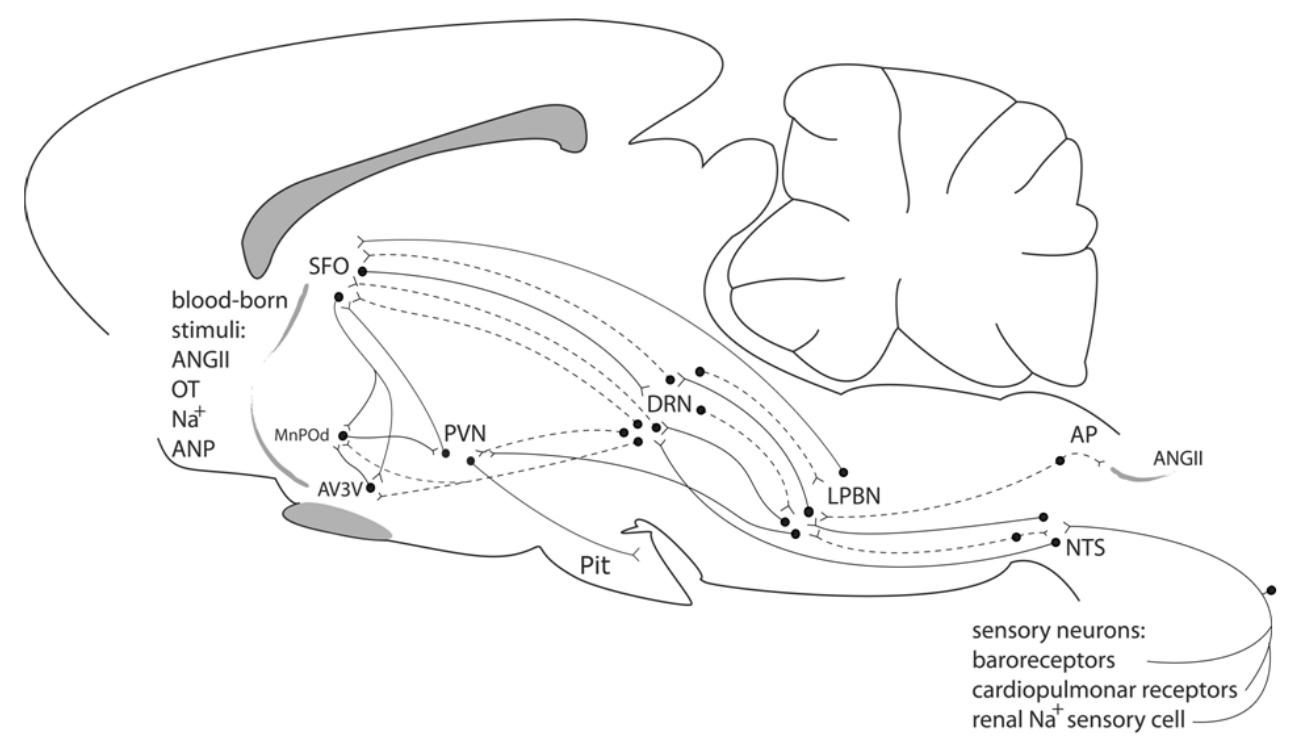

Fig. 2 - Schematic sagittal view of rat brain showing interconnections among area postrema (AP), wall of the anterior-ventral region of the third ventricle (AV3V, particularly the organum vasculosum laminae terminalis, OVLT), dorsal preoptic median nucleus (MnPOd), dorsal raphe nucleus (DRN), lateral parabrachial nucleus (LPBN), nucleus tractus solitarius (NTS), pituitary (Pit), paraventricular nucleus of the hypothalamus (PVN), subfornical organ (SFO). Continuous line represents typical 5-HTergic neurons from DRN and, broken line depicts 5-HT-containing neurons from AP and NTS. It is observed the bidirectional connections between SFO and DRN and LPBN and DRN putatively regarded to sodium modulation. Note the synapses among 5-HTergic and ANPergic neurons, at AV3V region and, oxytocinergic neurons, at PVN, related with oxytocin release control. SFO is represented with two subpopulations of neurons: ANG II-sensitive and $\mathrm{Na}^{+}$-sensing neurons. Humoral stimuli reach structures of the wall of AV3V region (OVLT, from which relay to MnPOd), SFO and AP and, sensory signals attain to NTS through the sensory neurons. Blood-borne signals are monitored by SFO, OVLT and AP. Both humoral, and sensory signals constitute multimodal information relayed from the neural lobe of pituitary (oxytocin), cardiomiocytes of right atrium (ANP), kidney-renin-angiotensin system (renin, ANG II), volume receptors, cardiopulmonary and arterial baroreceptors and putative renal $\mathrm{Na}^{+}$sensing mechanism. (See in Introduction and Conclusions; for a complement discussion see Denton 1984, Reis et al. 1994, Menani et al. 1996, Johnson and Thunhorst 1997, Fitzsimons 1998, McCann et al. 2003, Antunes-Rodrigues et al. 2004, Daniels and Fluharty 2004, Hiyama et al. 2004, McKinley and Johnson 2004, Cavalcante-Lima et al. 2005b).

anisms, through the gathering of parallel systems (e.g., subset of ascending 5-HTergic neurons), it would prevail, in contrast to a single hypothetical 5-HTergic pathway for the inhibition of the sodium appetite.

In our standpoint the regulating activity of those different channels of sodium appetite control are not excluding and it would be originated in different subset of 5-HTergic neurons of DRN. This speculation is based on the conception raised by Azmitia and Abrams, independently (Azmitia 1987, 2001, Abrams et al. 2004) according to which the 5-HTergic neurons develop intense collaborative activity in the terminal fields and in its origin in the raphe. Additionally, subpopulations of 5-HTergic neurons of DRN topographically organized would contain unique functional properties and be asso- ciated with the modulation of specific forebrain systems. Their presuppositions would support the experimental conclusions in which different stimuli that promote hyponatremia and/or volume depletion evoke similarly an increased sodium appetite in rats with deficit on the 5HTergic transmission or with DRN lesion. This hypothesis is possibly related with the activation of different forebrain modulatory systems.

It would also remain to be elucidated (i) the reciprocal functional relationships between DRN and LPBN (ii) the origin of the visceral sensory signals transmitters of deficits in the sodium concentration and ECF volume and of sodium filtered load in the renal tubules and (iii) the existence of signals of forebrain structures toward midbrain, transmitters of information about monitoring 
of plasma concentration of sodium, ANG II, ANP and other humoral factors. In a redundancy to these questions we cannot discard the possibility of the involvement of DRN in the integration of direct afferent visceral sensory signals concerning the volume regulation.

In a forthcoming perspective the physiological contexts should be investigated to clarify how these homeostatic systems are working. Furthermore, how are the time course that they would be activated and, the clinical correlation among the functional disturbance of the 5HTergic system and its correlation with the modulating system of sodium appetite?

\section{ACKNOWLEDGMENTS}

We are grateful to Mr Ipojucan Pereira de Souza by animal care. Part of the data related herein was performed in Laboratório de Fisiologia Animal, Departamento de Ciências Fisiológicas, Universidade Federal Rural do Rio de Janeiro and was partially supported by grants from Programa de Apoio a Núcleos de Excelência (PRONEX), Conselho Nacional de Desenvolvimento Científico e Tecnológico (CNPq) and Fundação Carlos Chagas Filho de Amparo à Pesquisa do Estado do Rio de Janeiro (FAPERJ).

\section{RESUMO}

Este artigo revisa o papel do sistema serotoninérgico no controle do apetite ao sódio. Dados derivados da administração periférica e icv de agentes serotoninérgicos demonstraram a participação de receptores 5-HT2/3 na modulação do apetite ao sódio. Estas observações foram estendidas com os estudos realizados após a depleção cerebral de serotonina, lesões do NDR e durante o bloqueio 5-HT2A/2C no núcleo parabraquial lateral (NPBL). A depleção cerebral de serotonina e as lesões do NDR aumentaram o apetite ao sódio, em condições basais, após depleção de sódio, durante a hipovolemia ou após a estimulação beta-adrenérgica. Estas evidências suscitaram a hipótese de que a supressão de vias ascendentes do NDR, possivelmente 5-HT, alteram os mecanismos angiotensinérgicos e a atividade dos sensores de sódio do órgão subfornicial envolvidos no controle do apetite ao sódio. O bloqueio serotoninérgico no NPBL induziu a resultados similares, particularmente aqueles relacionados com a resposta natriorexigênica provocada pela depleção de volume ou o aumento da ingestão de salina hipertônica induzida pela estimulação angiotensinérgica cerebral. Em resumo, as evidências convergem para a admissão de uma participação integrada resultante da interação recíproca entre NDR e NPBL objetivando controlar o apetite ao sódio.

Palavras-chave: equilíbrio hidroeletrolítico, apetite ao sódio, sistema serotoninérgico, núcleo dorsal da rafe, núcleo parabraquial lateral, agentes serotoninérgicos.

\section{REFERENCES}

ABRAms JK, JOHSON PL, Hollis JH AND LOWRY CA. 2004. Anatomic and functional topography of the dorsal raphe nucleus. Ann New York Acad Sci 1018: 46-57.

Aghajanian GK, Sprouse JS and Rasmussen K. 1987. Physiology of the midbrain serotonin system. In: PSYChopharmacology: The Third Generation of Progress, New York, Raven Press, p. 141-149.

Amat J, Tamblyn JP, Paul ED, Bland St, Amat P, Foster AC, Watkins LR AND MAIER SF. 2004. Microinjection of urocortin 2 into the dorsal raphe nucleus activates serotonergic neurons and increases extracellular serotonin in the basolateral amygdala. Neuroscience 129: 509-519.

Amico JA, Morris M And Vollmer RR. 2001. Mice deficient in oxytocin manifest increased saline consumption following overnight fluid deprivation. Am J Physiol 281: R1368-R1378.

ANDERSSON B. 1952. Polydipsia caused by intrahypothalamic injections of hypertonic $\mathrm{NaCl}$ solutions. Experientia 15: $157-158$.

ANDERSSON B. 1971. Thirst and brain control of water balance. Am Sci 59: 408-415.

Andersson B. 1978. Regulation of water intake. Physiol Rev 58: 582-603.

ANDERSSON AND MCCANN SM. 1954. A further study of polydipsia evoked hypothalamic stimulation in the goat. Acta Physiol Scand 33: 333-346.

Antunes-Rodrigues J And Covian MR. 1963. Hypothalamic control of sodium chloride and water intake. Acta Physiol Lat Am 13: 94-100.

Antunes-Rodrigues J, MCCANn SM AND SAMSOM WK. 1986. Central administration of atrial natriuretic factor inhibits saline preference in the rat. Endocrinology 118: 1726-1728.

Antunes-Rodrigues J, Ramalho MJ, Reis LC, Menani JV, Turrin MQ, GutKowska J AND MCCANN SM. 1991. Lesions of the hypothalamus and pituitary inhibit volume expansion-induced release of atrial 
natriuretic peptide. Proc Nat Acad Sci USA 88: 2956 2960.

Antunes-Rodrigues J, De Castro M, Elias Ll, VALENÇA MM AND MCCANN SM. 2004. Neuroendocrine control of body fluid metabolism. Physiol Rev 84: 169-208.

Arbisi PA, Levine AS, Nerenberg J and Wolf J. 1996. Seasonal alteration in taste detection and recognition threshold in seasonal affective disorder; the proximate source of carbohydrate craving. Psych Res 59: $171-182$

Azmitia EC. 1987. The CNS serotonergic system: Progression toward a collaborative organization. In: PSYCHOPHARMACOlOGY: THE THIRD Generation OF Progress, New York, Raven Press, p. 61-73.

AZMitia EC. 2001. Modern views on an ancient chemical: Serotonin effects on cells proliferation, maturation, and apoptosis. Brain Res Bull 56: 413-424.

AzMitia EC AND SEgAL M. 1978. An autoradiographic analysis of the differential ascending projections of the dorsal and median raphe nuclei in the rat. J Comp Neurol 179: 641-668.

AZMitia EC, LIAO B AND CHEN YS. 1993. Increase of tryptophan hydroxylase enzyme protein by dexamethasone in adrenalectomized rat midbrain. J Neurochem 13: 5041-5055.

Badauê-Passos Jr D, Ventura RR, Silva LFS, OliVARes EL, Ramalho MJ, Antunes-Rodrigues J AND REIS LC. 2001. Effect of losartan on sodium appetite of hypothyroid rats subjected to water and sodium depletion and sodium and food deprivation. Exp Physiol 86: 621-628

Badauê-Passos Jr D, Ventura RR, Silva LFS, OliVARES EL AND REIS LC. 2003. Effect of brain serotoninergic stimulation on sodium appetite of euthyroid and hypothyroid rats. Exp Physiol 88: 251-260.

Bahner U, Geiger H, Palkovits M and Heidland A. 1988. Atrial natriuretic factor in specific brain areas of spontaneously hypertensive rats. Hypertension 12: 519524.

Belló AA AND Covian MR. 1988. Effect of the excess of thyroid hormone administration on water and sodium chloride intake in the rat. Physiol Behav 43: 155-157.

BELló AA AND COVIAN MR. 1991. Rats with spontaneous high level of $\mathrm{NaCl}$ intake have hypothyroidism. Physiol Behav 50: 1071-1073.

BERNARD C. 1878. Cours de Physiologie Générale du Mu- séum d'Histoire Naturelle. De la Vie Commune aux Animaux Végétaux, J. Ballière et fils, $404 \mathrm{p}$.

Bhatia S, Sircar SS And Ghorai BK. 1991. Taste disorder in hypo and hyperthyrodism. Indian J Physiol Pharmacol 35: 152-158.

Blackburn RE, SAMSOM WK, Fulton RJ, StRickeR EM AND Verbalis JG. 1995. Central oxytocin and ANP receptors mediate osmotic inhibition of salt appetite in rats. Am J Physiol 269: R245-R251.

Blair-West JR, Burns P, Denton DA, Ferraro T, MCBURNIE MI, TARJAN E AND WEISINGER RS. 1994. Thirst induced by increased brain sodium concentration is mediated by brain angiotensin. Brain Res 637: 335-338.

Blier P AND DE Montigny C. 1990. Electrophysiological investigation of the adaptive response of the 5-HT system to the administration of 5-HT1A receptor agonists. J Cardiovasc Pharmacol 15: S42-S48.

BOADLE-BIBER MC. 1993. Regulation of serotonin synthesis. Prog Biophys Mol Biol 60: 1-15.

Bosler O ANd Descarries L. 1988. Monoamine innervation of the organum vasculosum laminae terminalis (OVLT): A high resolution radioautographic study in the rat. J Comp Neurol 272: 545-561.

BRASZKO JJ, KARWOSKA-POLECKA W, HALICKA D AND GARD PR. 2003. Captopril and enalapril improve cognition and depressed mood in hypertensive patients. J Clin Physiol Pharmacol 14: 323-343.

BRown J AND CZARnecki A. 1990. Distribution of atrial natriuretic peptide receptor subtypes in rat brain. Am J Physiol 258: R1078-R1083.

Caruso-Neves C, Vives D, Dantas C, Albino CM, FonseCa LM, LARA LS, Iso M and Lopes AG. 2004. Ouabain-insensitive $\mathrm{Na}^{+}$-ATPase of proximal tubules is an effector for urodiladin and atrial natriuretic peptide. Biochim Biophys Acta 1600: 93-98.

Castro L, Athanazio R, Barvetta M, Ramos AC, angelo Al, Campos i, Varjao B, Fregoneze J And De Castro-E-Silva E. 2003. Central 5-HT2B/2C and 5-HT3 receptor stimulation decreases salt intake in sodium-depleted rats. Brain Res 981: 151-159.

Cavalcanti-Lima et Al. 2005a. Chronic excitotoxic lesion of dorsal raphe nucleus induces sodium appetite. Braz J Med Biol Res 38: 1669-1675.

CAVAlCANTI-Lima et AL. 2005b. Dipsogenic stimulation in ibotenic DRN-lesioned rats induces concomitant sodium appetite. Neurosci Lett 374: 5-10. 
Celada P, Casanovas JM, Paez X and Artigas F. 2002. Control of serotonergic neurons in the dorsal raphe nucleus by the lateral hypothalamus. Brain Res 932: 79-90.

Chaouloff F. 2000. Serotonin, stress and corticoids. J Psychopharmacol 14: 139-151.

Chaput Y, Lesieur P And de Montigny C. 1990. Effects of short-term serotonin depletion on the efficacy of serotonin neurotransmission: electrophysiological studies in the rat central nervous system. Synapse 6: 328-337.

Ciriello J. 1997. Afferent renal inputs onto subfornical organ neurons responsive to angiotensin II. Am J Physiol 272: R1684-R1689.

CiRiello J. 1998. Afferent renal inputs to paraventricular nucleus vasopressin and oxytocin neurosecretory neurons. Am J Physiol 275: R1745-R1754.

Clark MS AND Russo AF. 1997. Tissue-specific glucocorticoid regulation of tryptophan hydroxylase mRNA levels. Brain Res Mol Brain Res 48: 346-354.

Colombari DS, Menanin JV and Johnson AK. 1996. Forebrain angiotensin type 1 receptors and parabrachial serotonin in the control of $\mathrm{NaCl}$ and water intake. Am J Physiol 271: R1470-R1476.

Cooper JR, Bloom FE ANd Roth RH. 1996. Serotonin (5-Hydroxytryptamine) and Histamine. In: BLOOM FE ET AL. (Eds), The Biochemical Basis of Neuropharmacology, $7^{\text {th }}$ ed., Oxford University Press, New York, p. $352-409$.

COOPER SJ AND CicCOCIOPPO R. 1993. Effect of selective 5-HT1 agonists in water deprived rats on salt intake in twochoice tests. Pharmacol Biochem Behav 45: 513-518.

Cooper SJ, Fryer MJ and Neill JC. 1988. Specific effect of putative 5-HT1A, agonists, 8-OH-DPAT and gepirone, to increase hypertonic saline consumption in the rat. Evidence against a general hyperdipsic action. Physiol Behav 43: 533-537.

Covian MR And Antunes-Rodrigues J. 1963. Specific alterations in sodium chloride intake after hypothalamic lesions in the rat. Am J Physiol 205: 922-926.

DANiEls D And Fluharty SJ. 2004. Salt appetite: a neurohormonal viewpoint. Physiol Behav 81: 319-337.

Debold AJ, Bruneau BG and Debold MLK. 1996. Mechanical and neuroendocrine regulation of the endocrine heart. Cardiovasc Res 31: 7-18.

De Gobbi Ji, De Luca Jr LA and Menani JV. 2000. Serotonergic mechanisms of the lateral parabrachial nu- cleus on DOCA-induced sodium appetite intake. Brain Res 880: 131-138.

Denton D. 1984. The hunger for salt. An anthropological, physiological and medical analysis. Springer-Verlag, New York, USA, 650 p.

Denton D, Weisinger R, Mundy NI, Wickings EJ, Dixson A, Moisson P, Pingard AM, Shade R, CAREY D AND ARdaillou R. 1995. The effect of increased salt-intake on blood pressure of chimpanzees. Nat Med 10: 1009-1016.

Denton DA, McKinley MJ And Weisinger RS. 1996. Hypothalamic integration of body fluid regulation. Proc Nat Acad Sci USA 93: 7397-7404.

DiBona GF. 2001. Peripheral and central interactions between the renin-angiotensin system and the renal sympathetic nerves in control of renal function. Ann New York Acad Sci 940: 395-406.

ELFONT RM, EPSTEIN AN AND FITZSIMONS JT. 1984. Involvement of the renin-angiotensin system in captoprilinduced sodium appetite in the rat. J Physiol 354: 11-27.

ElhwUegi AS. 2004. Central monoamines and their role in major depression. Prog Neuropsychopharmacol Biol Psychiatry 28: 435-451.

FITCH GK AND WeISS ML. 2000. Activation of renal afferent pathways following furosemide treatment II. Effect of angiotensin blockade. Brain Res 861: 377-389.

Fitts DA, Thornton SN, RuhF AA, Zierath DK, JOHNSON AK AND THUNHORST RL. 2003. Effects of central oxytocin receptor blockade on water and saline intake, mean arterial pressure, and c-Fos expression in rats. Am J Physiol 285: R1331-R1339.

FITZSIMONS JT. 1998. Angiotensin, thirst, and sodium appetite. Physiol Rev 78: 583-686.

FRANCHINI LF, JOHNSON AK, DE OLMOS J AND ViVAS L. 2002. Sodium appetite and Fos activation in serotonergic neurons. Am J Physiol 282: R235-R243.

Franchini LF, Rubinstein M and Vivas L. 2003. Reduced sodium appetite and increased oxytocin gene expression in mutant mice lacking $\beta$-endorphin. Neuroscience 121: 875-881.

FRANCHINI LFM AND VIVAS L. 1995. Distribution of Fos immunoreactivity in rat brain after sodium consumption induced by peritoneal dialysis. Am J Physiol 276: R1180R1187.

GOLDIN ET AL. 2000. Nomenclature of voltage-gated sodium channels. Neuron 28: 365-368. 
Graeff FG, Viana MB and Mora PO. 1997. Dual role of 5-HT in defense and anxiety. Neurosci Biobehav Rev 21: 791-799.

Gutkowska J, Antunes-Rodrigues J AND MCCANN SM. 1997. Atrial natriuretic peptide in brain and pituitary gland. Physiol Rev 77: 465-515.

Haddjeri N, ORTEMANN C, DE MONTIGNy C AND BLIER P. 1999. Effect of sustained administration of the 5-HT1A receptor agonist flesinoxan on rat 5-HT neurotransmission. Eur Neuropsychopharmacol 9: 427-440.

Harris PJ, Hiranyachattada S, Antoine AM, WalKER L, REILly AM AND Eitle E. 1996. Regulation of renal tubular sodium transport by angiotensin II and atrial natriuretic factor. Clin Exp Pharmacol Physiol 3: S112S118.

Hiyama Ty, Watanabe E, Ono H, Inenaga K, TamKUM MM, Yoshida S AND NodA M. 2002. $\mathrm{Na}_{\mathrm{x}}$ channel involved in CNS sodium-level sensing. Nat Neurosci 4: 511-512.

Hiyama TY, Watanabe E, OKado H and Noda M. 2004. The subfornical organ is the primary locus of sodium-level sensing by $\mathrm{Na}_{\mathrm{x}}$ sodium channels for the control of salt intake behavior. J Neurosci 24: 9276-9281.

Hosono T, Schmid HA, Kanosue E AND Simon E. 1999. Neuronal actions of oxytocin on the subfornical organ of male rats. Am J Physiol 276: E1004-E1008.

Hoyer D, HANnON JP AND Martin GR. 2002. Molecular pharmacological and functional diversity of 5-HT receptors. Pharmacol Biochem Behav 71: 533-554.

Hutson PH, SARNA GS, O'CONNEL MT AND CURZON G. 1989. Hippocampal 5-HT synthesis and release in vivo is decreased by infusion of 8-OHDPAT into the nucleus raphe dorsalis. Neurosci Lett 100: 276-280.

INVERNIZZI R, CARLI M, DiCLEMENTE A AND SAMANIN R. 1991. Administration of 8-hydroxy-2-(di-n-propilamino) tetralin in raphe nuclei dorsalis and medianus reduces serotonin synthesis in the rat brain: Differences in potency and regional sensitivity. J Neurochem 56: $243-$ 247.

ITOH H ET AL. 1986. Centrally infused atrial natriuretic polipetide attenuates exaggerated salt appetite in spontaneously hypertensive rats. Circulation Res 59: 342-347.

JACOBS BL AND AZMitia EC. 1992. Structure and function of the brain serotonin system. Physiol Rev 72: 165-231.

Johnson AK AND ThUnhorst RL. 1997. The neuroendocrinology of the thirst and salt appetite: Visceral sensory signals and mechanisms of central integration. Front Neuroendocrinol 18: 292-353.
Jorgensen H, RiIs M, KNigge U, KJaer A AND WARBERG J. 2003. Serotonin receptors involved in vasopressin and oxytocin secretion. J Neuroendocrinol 15: 242-249.

Kirby LG, Rice KC AND VAlentino RJ. 2000. Effects of corticotropin-releasing factor on neuronal activity in the serotonergic dorsal raphe nucleus. Neuropsychopharmacol 22: 148-162.

Lima HRC, CAVAlCANTE-LIMA HR, CEDRAZ-MERCERZ PL, Costa-e-Sousa RH, Olivares EL, BadauêPassos Jr D, Medeiros MA, Côrtes WS and Reis LC. 2004. Brain serotonin depletion enhances the sodium appetite induced by sodium depletion or beta-adrenergic stimulation. An Acad Bras Cienc 76: 85-92.

LIND RW. 1986. Bi-directional, chemically specified neural connections between the subfornical organ and midbrain raphe system. Brain Res 384: 250-261.

LOWRY CA. 2002. Functional subsets of serotonergic neurones: implications for control of the hypothalamic-pituitary-adrenal axis. J Neuroendocrinol 14: 911-923.

MAIER SF AND WATKINS LR. 1998. Stressor controllability, anxiety, and serotonin. Cogn Ther Res 22: 595-613.

McCann SM, Franci CR, Favaretto AL, Gutkowska J AND ANTUnes-RodRIGUES J. 1997. Neuroendocrine regulation of salt and water metabolism. Braz J Med Biol Res 30: 427-441.

MCCANn SM, GutKowska J AND ANTUnES-RodRigueS J. 2003. Neuroendocrine control of body fluid homeostasis. Braz J Med Biol Res 36: 165-181.

MCKInley MJ AND Johnson AK. 2004. The physiological regulation of thirst and fluid intake. News Physiol Sci 19: $1-6$.

McKinley MJ, McAllen RM, Davern P, Giles ME, Penschow J, Sunn N, Uschakov A And OldField BJ. 2003. The sensory circumventricular organs of the mammalian brain. Adv Anat Embriol Cell Biol 171: IIIXII, 1-122.

Meltzer HY AND LOWy MT. 1987. The serotonin hypothesis of depression. In: PSYCHOPHARMACOLOGY: THE Third Generation of Progress, New York, Raven Press, p. 513-526.

Menani JV, Thunhorst RL and Johnson AK. 1996. Lateral parabrachial nucleus and serotonergic mechanisms in the control of salt appetite in rats. Am J Physiol 270: R162-R168.

Menani JV, Colombari DS, Beltz TG, Thunhorst RL AND JOHNSON AK. 1998a. Salt appetite: interaction of forebrain angiotensinergic and hindbrain serotonergic mechanisms. Brain Res 801: 29-35. 
Menani JV, De Luca Jr LA and Johnson AK. 1998b. Lateral parabrachial nucleus serotonergic mechanisms and salt appetite induced by sodium depletion. Am J Physiol 274: R555-R560.

Menani JV, Barbosa SP, De Luca Jr LA, De Gobbi Ji AND Johnson AK. 2002. Serotonergic mechanisms of the lateral parabrachial nucleus and cholinergic-induced sodium appetite. Am J Physiol 282: R837-R841.

MISELIS RR. 1981. The efferent projections of the subfornical organ of the rat: a circumventricular organ within a neural network subserving water balance. Brain Res 230: $1-23$.

Moe KE, Weiss ML And Epstein AN. 1984. Sodium appetite during captopril blockade of endogenous angiotensin II formation. Am J Physiol 247: R356-R365.

Montes R AND JOHnson AK. 1990. Efferent mechanisms mediating renal sodium and water excretion induced by centrally administered serotonin. Am J Physiol 259: R1267-R1273.

Moulik S, Speth RC, Turner BB And Rowe BP. 2002. Angiotensin II receptor subtype distribution in the rabbit brain. Exp Brain Res 142: 275-283.

Muldoon MF, Sved AF, Flory JD, Perel JM, MATTHEWS KA AND MANNUCK SB. 1998. Inverse relationship between fenfluramine-induced prolactin release and blood pressure in humans. Hypertension 32: 972-975.

NeILl JC AND CoOper SJ. 1989. Selective reduction by serotonergic agents of hypertonic saline consumption in rats. Evidence for 5-HT1C receptor mediation. Psychopharmacol 99: 196-201.

Neumeister A. 2003. Tryptophan depletion, serotonin, and depression: where do we stand? Psychopharmacol Bull 37: 99-115.

Olivares EL, Costa-E-Sousa RH, CaValcante-Lima HR, Lima HRC, Cedraz-Mercez PL and Reis LC. 2003. Effect of electrolytic lesion of the dorsal raphe nucleus on water intake and sodium appetite. Braz J Med Biol Res 36: 1709-1716.

O'Reardon JP, Chopra MP, Bergan A, Gallop R, DERUbeIS RJ AND CRITS-CHRISTOPH P. 2004. Response to tryptophan depletion in major depression treated with either cognitive therapy or selective serotonin reuptake inhibitor antidepressants. Biol Psychiatry 55: 957-959.

Palkovits M, Geiger H, Bahner U, Fodor M And PAMMER C. 1990. Atrial natriuretic factor in central ner- vous system regulatory mechanisms: effect of experimental alterations in water and salt homeostasis and blood pressure. Miner Electrolyte Metab 16: 42-47.

Parent A, Descarries L and Beaudet A. 1981. Organization of ascending serotonin systems in the adult rat brain. A radioautographic study after intraventricular administration of $\left[{ }^{3} \mathrm{H}\right] 5$-hydroxytryptamine. Neuroscience 6: 115-138.

Petrov T, Jhamandas JH AND KRUKOFF TL. 1992a. Characterization of peptidergic efferents from the lateral parabrachial nucleus to identified neurons in the rat dorsal raphe nucleus. J Chem Neuroanat 5: 367-373.

Petrov T, Krukoff TL and Jhamandas JH. 1992b. The hypothalamic paraventricular and lateral parabrachial nuclei receive collaterals from raphe nucleus neurons: a combined double retrograde and immunocytochemical study. J Comp Neurol 318: 18-26.

QUIRION R. 1989. Receptor site for atrial natriuretic factors in brain and associated structures: an overview. Cell Mol Neurobiol 9: 45-55.

Ramalho MJ, Reis LC, Nonaka K, Antunes-RodriGues J AND DE-CASTRO-E-Silva E. 1990. Thyroidectomy reduces stress-induced prolactin secretion in rats. Participation of brain serotonergic system. Braz J M Biol Res 23: 747-750.

Rattray M, Baldessari S, Gobbi M, Mennini T, SAMANIN R AND BENDOTTI C. 1996. p-Chlorphenylalanine changes serotonin transporter mRNA levels and expression of the gene product. J Neurochem 67: 463-472.

REID IA, MorRIs BJ AND GANONG WF. 1978. The reninangiotensin system. Ann Rev Physiol 40: 377-410.

Reis LC, Ramalho MJ AND Antunes-Rodrigues J. 1990a. Central serotonergic modulation of drinking behavior induced by water deprivation: effect of a serotonergic agonist (MK-212) administered intracerebroventricularly. Braz J Med Biol Res 23: 1335-1338.

Reis LC, Ramalho MJ And Antunes-Rodrigues J. 1990b. Central serotonergic modulation of drinking behavior induced by angiotensin II and carbachol in normally hydrated rats: effect of intracerebroventricular injection of MK-212. Braz J Med Biol Res 23: 1339-1342.

Reis LC, Ramalho MJ And Antunes-Rodrigues J. 1991a. Effect of central administration of serotoninergic agonists on electrolyte excretion control. Braz J M Biol Res 24: 633-641.

Reis LC, Ramalho MJ And Antunes-Rodrigues J. 1991b. Participation of the median raphe nucleus and 
central serotoninergic pathways in the control of water electrolyte excretion. Braz J M Biol Res 24: 847-857.

Reis LC, Ramalho MJ And Antunes-Rodrigues J. 1992. Brain serotoninergic stimulation reduces the water intake induced by systemic and central beta-adrenergic administration. Braz J Med Biol Res 25: 529-536.

Reis lC, Ramalho MJ, Favaretto AL, Gutkowska J, MCCANn SM AND ANTUnes-Rodrigues J. 1994. Participation of the ascending serotonergic system in the stimulation of atrial natriuretic peptide release. Proc Nat Acad Sci USA 91: 12022-12026.

Rigatto K, Puryear R, Bernatova I and Morris M. 2003. Salt appetite and the renin-angiotensin system: effect of oxytocin deficiency. Hypertension 42: 793-797.

Rouah-Rosilio M, Orosco M AND NicOlaidis S. 1994. Serotoninergic modulation of sodium appetite in the rat. Physiol Behav 55: 811-816.

SaAd WA, Guarda IF, Camargo LA, Santos TA, SimÕES S AND SAAD WA. 2002. Adrenoceptors of the medial septal area modulate water intake and renal excretory function induced by central administration of angiotensin II. Braz J M Biol Res 35: 951-959.

SAAVEDRA JM. 2005. Brain Angiotensin II: New Developments, Unanswered Questions and Therapeutic Opportunities. Cell Mol Neurobiol 25: 485-512.

SAAVEDRA JM AND KURIHARA M. 1991. Autoradiography of atrial natriuretic peptide (ANP) receptors in the rat brain. Can J Physiol Pharmacol 69: 1567-1575.

Saydoff JA, Rittenhouse PA, VAnd De Kar LD AND BROWNFIELD MS. 1991. Enhanced serotonergic transmission stimulates oxytocin secretion in conscious male rats. J Pharmacol Exp Ther 257: 95-99.

SCHNERMANN J AND LEVINE DZ. 2003. Paracrine factors in tubuloglomerular feed-back: adenosine, ATP, and nitric oxide. Ann Rev Physiol 65: 501-529.

SCHULKIN J. 1991. Sodium hunger: The search for a salty taste. Cambridge University Press, New York, USA.

SCROGIN KE, JoHnson AK AND SCHMID HA. 1998. Multiple receptor subtypes mediate the effects of serotonin on rat subfornical organ neurons. Am J Physiol 275: R2035-R2042.

SOARES TJ ET AL. 1999. Atrial natriuretic peptide and oxytocin induce natriuresis by release of cGMP. Proc Nat Acad Sci USA 96: 278-283.

Song K, Allen AM, PAxinos G And Mendelsohn FA. 1992. Mapping of angiotensin II receptor subtype heterogeneity in rat brain. J Comp Neurol 316: 467-484.
SPROUSE JS AND AGHAJANIAN GK. 1987. Electrophysiological responses of serotoninergic dorsal raphe neurons to 5-HT1A and 5-HT1B agonists. Synapse 1: 3-9.

Stocker SD, Muldoon MF ANd Sved AF. 2003. Blunted fenfluramine-evoked prolactin secretion in hypertensive rats. Hypertension 42: 719-724.

STRICKER EM AND Verbalis JG. 1996. Central inhibition of salt appetite by oxytocin in rats. Regul Pept 66: 83-85.

Tanaka J, Ushigome A, Hori K and Nomura M. 1998. Responses of raphe nucleus projecting subfornical organ neurons to angiotensin II in rats. Brain Res Bull 45: 315-318.

Tanaka J, OKumura T, Sakamaki K and Miyakubo H. 2001. Activation of serotonergic pathways from the midbrain raphe system to the subfornical organ by hemorrhage in the rat. Exp Neurol 169: 156-162.

Tanaka J, Hayashi Y, Yamato K, Miyakubo H and NOMURA M. 2004. Involvement of serotonergic systems in the lateral parabrachial nucleus in sodium and water intake: a microdalysis study in the rat. Neurosci Lett 357: 41-44.

TAYLOR R AND FREGLY MJ. 1964. Renal response of propylthiouracil-treated rats to injected mineralocorticoids. Endocrinology 75: 33-41.

Thunhorst RL, FitTs DA And Simpson JB. 1989. Angiotensin-converting enzyme in subfornical organ mediates captopril-induced drinking. Behav Neurosci 103: 1302-1310.

Thunhorst RL, Kirby RF And Johnson AK. 1996. Role of renal nerves in sodium depletion-induced salt appetite. Am J Physiol 271: R806-R812.

Thunhorst RL, Beltz TG and Johnson AK. 1999. Effects of subfornical organ lesions on acutely induced thirst and salt appetite. Am J Physiol 277: R56-R65.

TYCE GM. 1990. Origin and metabolism of serotonin. J Cardiovasc Pharmacol 16: S1-S7.

VACCARI A. 1982. Decreased central serotonin function in hypothyroidism. Eur J Pharmacol 82: 93-95.

Ventura RR, Olivares El, Badauê-Passos Jr D, Ramalho MJ, ANTUnes-Rodrigues J And ReIS LC. 2001. Effect of chronic oral administration of a low captopril dose on sodium appetite of hypothyroid rats. Influence of aldosterone treatment. Braz J M Biol Res 34: 407-411.

Ventura RR, Gomes DA, Reis WL, Elias LL, Castro M, Valença MM, Carnio EC, Rettori V, 
MCCAnn SM AND Antunes-Rodrigues J. 2002. Nitrergic modulation of vasopressin, oxytocin and atrial natriuretic peptide secretion in response to sodium intake and hypertonic blood volume expansion. Braz J M Biol Res 35: 1101-1109.

VoIsIn DL AND BouRQUe CW. 2002. Integration of sodium and osmosensory signals in vasopressin neurons. Trends Neurosci 25: 199-205.
Weisinger RS, BLAir-West JR, CHEN N, Burns P AND WEISINGER HS. 2004. Neurobiology of Sodium Appetite. In: NeURobIOLOGY OF Food AND Fluid INTAKE, $2^{\text {nd }}$ ed., STRICKER E AND Woods S (Eds), Handbook of Behavioral Neurobiology, Kluwer Academic, Plenum Publishers, New York, USA 14: 545-585.

WURTMAN RJ AND WURTMAN JJ. 1989. Carbohydrates and depression. Sci Am 260: 68-75. 